\title{
Development Of Cost-Saving Energy For Home Lighting Based Microcontroller and RTC
}

\author{
Benriwati Maharmi* \\ Electrical Engineering Department, \\ Sekolah Tinggi Teknologi Pekanbaru \\ (STTP), Indonesia
}

\author{
Toriq Kardova \\ Electrical Engineering Department, \\ Sekolah Tinggi Teknologi Pekanbaru \\ (STTP), Indonesia
}

\author{
Ermawati \\ Electrical Engineering Department, \\ Sekolah Tinggi Teknologi Pekanbaru \\ (STTP), Indonesia
}

*corresponding author: Benriwati Maharmi,benriwati_m@yahoo.com

\begin{abstract}
The use of controlled and efficient electrical energy can save the cost of electricity expenditure. This study aims to design the cost saving energy tool for household scale of lighting using automatic microcontroller system. The design of the appliance used the automatic control system of home lights, which setting time using RTC (Real Time Clock) and a microcontroller Arduino Mega 2560. Power supply on this system was operated to supply power all existing components and controller using Arduino Mega 2560 microcontroller. Based on the test results, the cost-saving energy tool worked as an expectation of controlling the On/Off lights automatically, the RTC and current sensors can work properly to limit the current. Therefore, this design proposed can reduce the cost of electrical energy.
\end{abstract}

Keywords-Cost saving energy, home lighting, microcontroller.

\section{INTRODUCTION}

Effective and efficient electricity usage is necessary to limit a load of electric current as required. Recently, the development of a cost-saving energy tool has been needed to facilitate everyone's work in turning off and turning on the lights quickly, precisely, flexibly and efficiently. One tool/system capable of monitoring and controlling the use of electrical energy is the microcontroller [1]. The microcontroller is a chip, which a complex integrated circuit that processes data from inputs received on a digital system. The microcontroller is a series of electronic components consisting of a microprocessor, RAM, ROM, timer, parallel, and serial I/O components, and interrupt controller [2].

Several studies have been done to research saving electrical energy such as Shalat (2015) [3] conduct research to control home lighting automatically using PLC Omron and timer control in internal PLC. Dange and Gondi (2011) [4] was researching saving energy for a home automation system using Power-Line Communication. However, there are advantages of using PLC due to costly and also less efficient if only used as a light controller only. Also, the internal control system of the timer using PLC is strongly influenced by the continuity of the power supply. If the PLC breaks down due to PLN power supply being suppressed, the timer will be reset to the initial time, so the internal control timer on the PLC is less accurate.
Furthermore, Wiyatno (2005) [5] performs a home appliance controller automatically using a digital timer and Atmel 89S52 microcontroller. This tool can only control the automation of On/Off home appliances, and cannot monitor the amount of current on the load of the household appliances. Furthermore, Panna et al. (2013) [6] was done a prototype of a smart home for energy saving using a microcontroller PIC18F458 to determines the lights to switch on/off and the fan speed setting. More, Arun \& Vuttaradi (2013) [7] conducted to design an efficient light control system using a microcontroller as well. Therefore, they stated the proposed tool/system that likely runs properly.

House lighting is usually placed on the terrace or the front yard, living room, bedroom, bathroom, kitchen, garage, backyard, and others. Currently, many workers or businessmen are working from the morning and coming home late at night, so the lighting in their house is often not turned on or off. As a result, electricity costs incurred each month more expensive, whereas homeowners rarely are at home on weekdays due to work factors. Furthermore, a saving energy tool is required to control the load current in the house automatically. Subsequence, it can reduce the cost of electricity bills. The home automation to save the energy cost may lead to convenience, comfort, security, and energy efficiency [7-10].

The purpose of this research is to design a system to control the use of electrical energy (cost-saving energy) with automatic control of home lighting using Arduino Mega 2560 microcontroller and the RTC. This tool is designed to control the use of electric current load on the house that can turn on and turn off the home lighting automatically with a predetermined time, thereby providing a cost-effective impact of electrical energy.

\section{LITERATURE REVIEW}

Cost-Saving energy is the act of reducing the amount of energy use. Energy savings can be achieved by energy use efficiently where the same benefits are obtained by using less energy, or by reducing consumption and energy use activities. Energy savings can lead to reduced costs, as well as increased environmental values, state security, personal security, and 
comfort. Organizations and individuals can save money by making energy savings, while commercial and industrial users can improve efficiency and profit by energy savings.

Energy saving is an important element of energy policy. Energy savings reduce energy consumption and energy demand per capita, so as to cover increasing energy demand due to population growth. This reduces energy costs and can reduce the need for energy generation or energy imports.

\section{A. Microcontroller Arduino}

The Arduino type used in this study is the Arduino Mega 2560. The Arduino Mega 2560 is a microcontroller board based on Atmega 2560, which has 54 digital input/output pins (15 can be used as PWM output), 16 analog inputs, 4 UART (serial port hardware), $16 \mathrm{MHz}$ crystal oscillator, USB connection, power jack, ICSP header, and reset button [11]. The authors' consideration is using Arduino Mega 2560 due to Arduino Mega 2560 has more digital I/O when compared to other types of Arduino. It has offered more flexibility due to input/output for control the load can be more [11].

\section{B. RTC (Real Time Clock)}

The RTC (Real Time Clock) is an electronic clock in the form of a chip that can calculate the time (from seconds to years) accurately and keep the data in real time. Because, the clock is working in real time, then the data output directly stored or sent to other devices through the system interface.

The RTC chips are often found on PC motherboards (usually located near the BIOS chip). All computers use RTC as it keeps the current clock information on the computer. The RTC is equipped with a battery for supplying power to the chip, so the clock will stay up-to-date even if the computer is turned off. RTC is rated quite accurate as a timer because it uses a crystal oscillator. In this paper, an RTC type has used a type of RTC DS1307 with 56 bytes of RAM to store data [12].

\section{Display of LCD [13]}

LCD Display a liquid crystal or electronic device that can be used to display numbers or text. There are two main types of LCD screens that can display numerically (used in watches, calculators, etc.) and display alphanumeric text (used on copy machines and mobile phones). In this numerical display, the crystals are formed into bars, and in alphanumeric displays, the crystals are only set into a point pattern. Each crystal has an individual electrical connection so it can be controlled independently. When the crystal is off '(ie no current passes through the crystal) the crystal light looks the same as the background material, so the crystal can't be seen. But when an electric current passes through a crystal, it changes shape and absorbs more light. This makes the crystals look darker than the sight of the human eye so that the point or bar shape can be seen from different backgrounds. The LCD used in this research was a type of LCD 20X4 with I2C, which have 4 line displays, where each row has 20 columns. The I2C LCD backpack aims to reduce the number of pins used on the connection between Arduino microcontroller with character LCD [13].

\section{Keypad Matrix}

The matrix of the keypad are buttons arranged by a matrix (row x columns) so as to reduce the use of input pins. For example, the keypad $4 \times 4$ matrix simply uses 8 pins for 16 keys. This is possible because the series of buttons arranged horizontally to form a line and vertically form a column.

The process of checking of the knob arranged in a matrix is by scanning technique, that is checking process done by giving the data feed in one part and checking the feedback on the other part. In this case, the feeding of data is done on the line section and checking feedback on the column. At the time of giving the data-feeds on one line, then the other line must be in inversion condition. The pressed button can be determined by looking at the origin of the data and in which column the data is detected. In this paper, it was consideration of the keypad matrix because the matrix keypad can save digital port microcontroller input used [14].

\section{E. Modul Relay SRD-05VDC-SL-C [15]}

This 5 volt of relay module is assembled using relay and optocoupler as its driver. It can be directly used or can be directly controlled using Arduino. Figure 1 is depicted the SRD-05VDC-SL-C relay module.

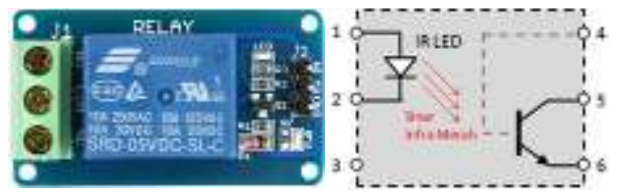

Figure 1. Modul Relay SRD-05VDC-SL-C [15]

\section{F. Sensor Arus ACS712}

The ACS712 is a Hall Effect current sensor. Hall effect allegro ACS712 is a precision sensor as AC or DC current sensor in current readings in industrial, automotive, commercial and communications systems. In general, this sensor application is switched-mode power supplies and overload protection [16].

\section{G. Universal Power Supply Adapter}

The universal power supply adapter is a useful circuit for converting high voltage AC $220 \mathrm{~V}$ to $12 \mathrm{~V}$ DC low voltage, where the output voltage of $12 \mathrm{Vdc}$ will be used to supply power to Arduino Mega 2560. Ideally, a power supply can produce a clean output, with a constant output voltage maintained with a tolerance level of input voltage, power load, as well as working temperature, with a $100 \%$ efficiency conversion rate [17]

\section{METHOD}

The design of this cost-saving energy tool consists of hardware design such as power supply circuit, I/O circuit to home light load, power adapter, Arduino Mega 2560 microcontroller, the RTC (Real Time Clock), display of LCD, matrix keypad, relay module, and ACS712 current sensor. Then, the design of the software was the setting of the clock and the current data. After that, the system was also alternatives to turn the lights manually via the switch On/Off. 
This tool uses 4 inputs: (1) Keypad functions to input data input current settings and timer time to turn the lights on and off, (2) ACS712 current sensor serves to measure the outflow current on the light load, (3) Real Time Clock (RTC) function to determine the time to turn off and turn on the lights and (4) On/Off switch to turn on and turn off the light manually. Furthermore, the cost-saving energy tool uses two outputs: Liquid Crystal Display (LCD) function displays input issued by Matrix Keypad, and Relay Module controls ON/OFF lights with NO (Normally Open) and NC (Normally Close) system on the relay. Data processing on this tool used Arduino Mega 2560 Microcomputer. In Figure 1 is presented a diagram of bock system for the design of a cost-saving energy tool.

From the block diagram in Figure 8 is shown the system works as follows: current sensor on the system using ACS712, a current sensor with a maximum current capacity of 5 amperes, this current sensor is used to read the current flowing on the load of the house lamps. Then combined with Real Time Clock (RTC), would be created a program to set how much maximum current that can be used by consumers at certain hours. For example, it was specified at 18.00 until 21.00 the current that can be used was 1 ampere or enough to turn on all the lights. Then at 21.00 until 05.00 the current that can be used was 0.4 ampere that enough to turn on two lights. To adjust the settings were used matrix keypad and also LCD display to see the time and flow of display. To adjusting the on and the off of the lamps were automatically used circuit releases that were connected with the load of the house lamps.

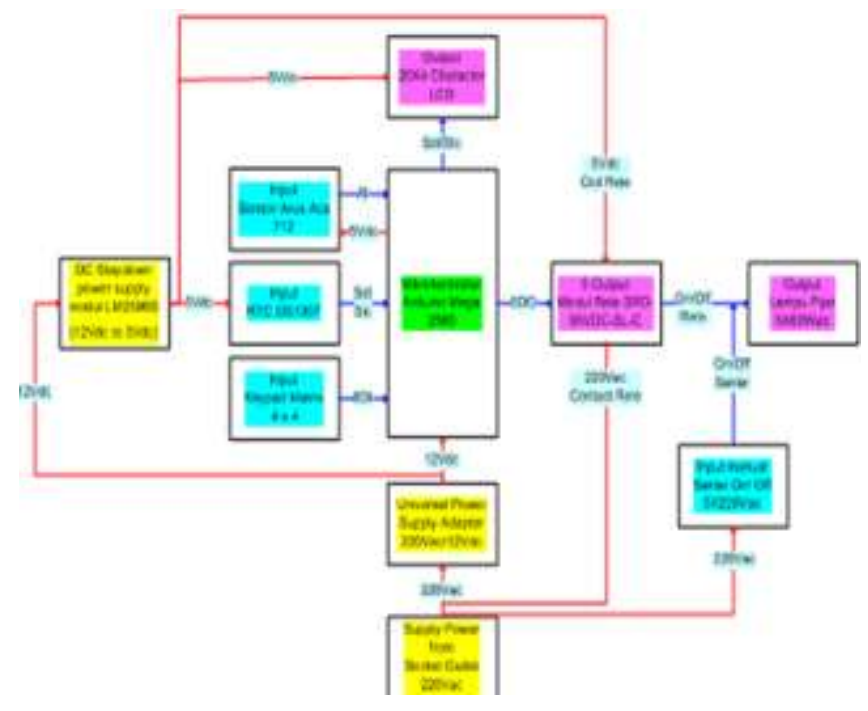

Figure 2. Diagram of a block system for cost-saving energy tool

\section{RESULTS AND DISCUSSION}

The result of this paper discussed the tool of power saving energy design that divided by hardware and software. The detailed design is discussed such as the selected of components, design of the circuit systems input and output. The software system for this paper was developed by using the Arduino software developer to design the Arduino controller program for energy saving tool. Furthermore, the proposed tool of energy saving was tested by the implementation of 5 lamps of home lighting.

\section{A. Result}

Design of hardware consists of a power supply circuit design for a power adapter and power supply to load such as lamps. Then, I / O circuit to home light load, power adapter, Arduino Mega 2560 microcontroller, the RTC (Real Time Clock), display of LCD, matrix keypad, relay module, and ACS712 current sensor

\section{Designing power supply circuits}

The designed system required an alternating voltage source of $220 \mathrm{Vac}$ and two direct-voltage sources of $12 \mathrm{Vdc}$ and $5 \mathrm{Vdc}$.

a. The alternating voltage source (AC) was obtained directly from the home installation socket 220Vac 6A. This voltage was used to supply power to power adapter 220Vac / $12 \mathrm{Vdc} 03 \mathrm{~A}$ and supply power to home lamp load (5X60Watts), that can be seen in Figure 3 and 4.

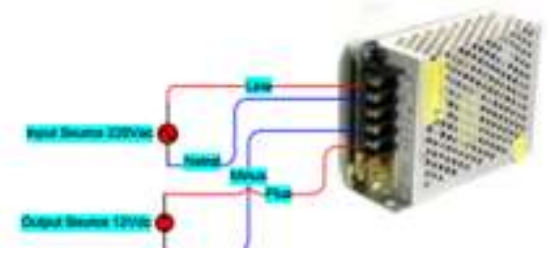

Figure 3. The circuit of power supply adapter $220 \mathrm{Vac} /$ $12 \mathrm{Vdc} 3 \mathrm{~A}$

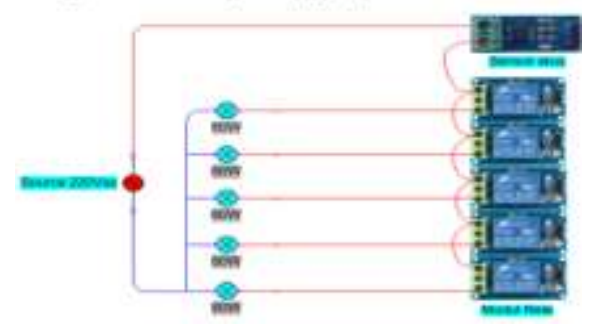

Figure 4. The power supply circuit to the 5X60watt home lights loads

\section{A direct voltage source (DC)}

The $12 \mathrm{Vdc}$ voltage source was obtained from power supply Adapter $220 \mathrm{Vac} / 12 \mathrm{Vdc} 3 \mathrm{~A}$. This $12 \mathrm{Vdc}$ voltage source was used for power supply to Arduino Mega 2560 Microcontroller and to DC-DC Stepdown power supply LM2596S-5.0 (12 Vdc to $5 \mathrm{Vdc}$ ), that can be seen in Figure 5 and 6.

The source voltage of $5 \mathrm{Vdc}$ was obtained from DC-DC Step-down power supply LM2596S-5.0 (12 Vdc to 5Vdc) 3A. This $5 \mathrm{Vdc}$ voltage source was used to supply power to Real Time Clock RTC DS1307 Module and to Relay Module SRD05VDC-SL-C, that can be seen in Figure 7 and 8.

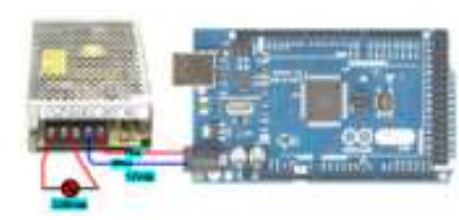

Figure 5. Power supply circuit to Arduino Mega 2560 


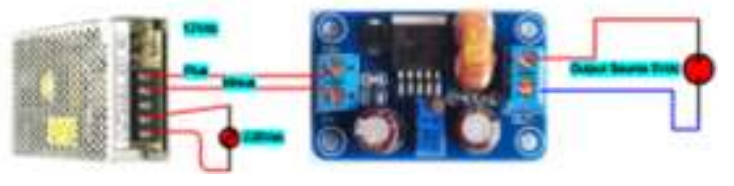

Figure 6. The circuit of power supply to DC Stepdown $05 \mathrm{Vdc}$

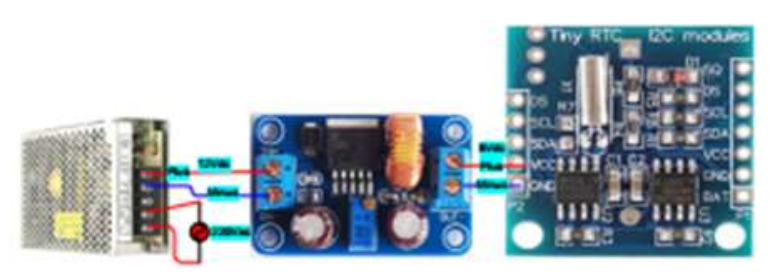

Figure 7. The power supply circuit to Timer RTC DS1307

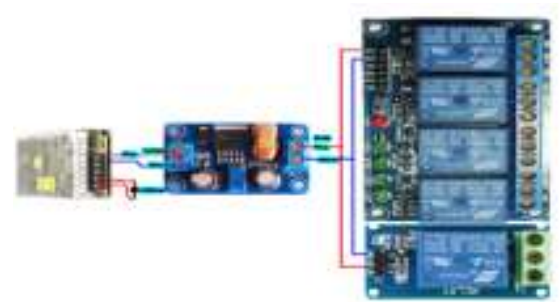

Figure 8. The power supply to Module Relay SRD-05VDCSL-C

The design of the circuit of the Display LCD 20X4 Character is depicted in Figure 9.

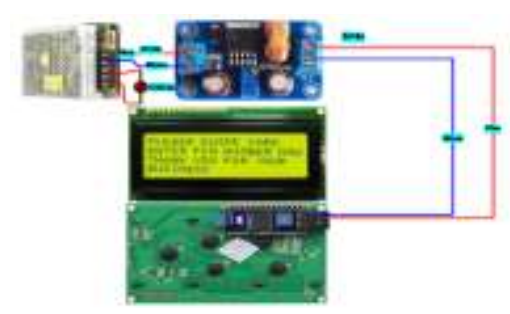

Figure 9. The circuit of power supply to Display LCD $20 X 4$ Character

\section{The design of the circuit of input}

The circuit has 16 inputs consist of 11 inputs connected to the microcontroller that were 8 Keypad Matrix inputs, 1 current sensor input, and 2 Real Time Clock inputs. And, the 5 inputs were On/Off switches that connect directly to the light loads. That is depicted in Figure 10 and 11.

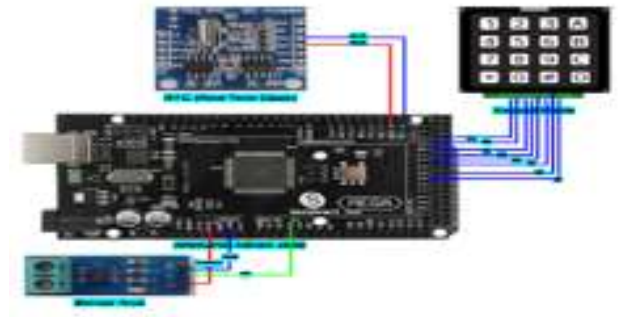

Figure 10. The input circuit connected to the microcontroller

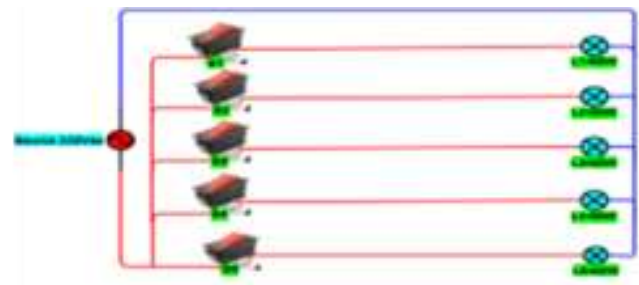

Figure 11. The five input switches On / Off connected to the lamps

\section{Design of output circuit}

The circuit output has 12 outputs consisting of 7 output modules connected to the microcontroller, 5 outputs to the relay coil and 2 outputs to the LCD display. And, 5 pieces of lights were connected to the 5 contacts NO (Normally Open) of the relay module. That circuits can be seen in Figure 12 and 13.

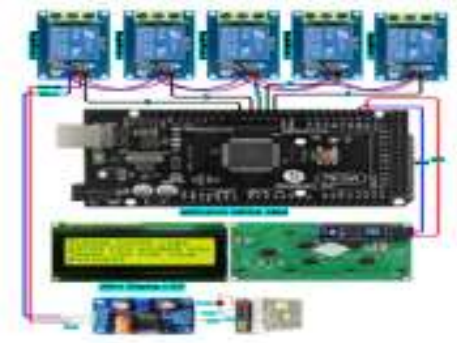

Figure 12. The output circuit connected to the microcontroller

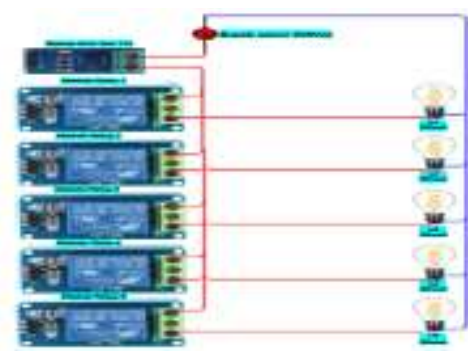

Figure 13. The output circuit of five relay modules connected to 5X60 Watt lamps loads 
The software program design

The design of the software program was used to control operational terminals and sustained input or output data ports, which it has to process executing data commands. In this paper, the system is worked after the clock time data was set. The data of setting time and current data were stored in the program memory of the microcontroller. In this paper, there was three data storage memory, so in this system can be stored up to three varying the data set of time clock and currents. Then, for the magnitude of the current flowing in the load, the lamps were controlled by the current sensor. If the current at the lamp load was greater than the setting of the feeding current the lamp would be turned off, and if the current on the light load was smaller than the current setting then the lamp would be switched on. To implemented the system was made a program for cost-saving energy tool. To create and process the program data is required: 1-unit laptop / PC with Windows OS 7 or higher and Software Arduino IDE 1.6.5, which serves to create and process cost-saving energy program. Also, it used the USB cable for data communication from laptop / pc to Arduino board (1 piece of Arduino Mega 2560 board).

\section{CONCLUSION}

The design of cost-saving energy tool based microcontroller Arduino Mega 2560 and RTC is conducted in this paper. The design consists of hardware design such as power supply circuit, I/O circuit to home light load, power adapter, Arduino Mega 2560 microcontroller, the RTC (Real Time Clock), display of LCD, matrix keypad, relay module, and ACS712 current sensor. Then, the design of the software was the setting of the clock and the current data. Based seven days implemented the tool testing was defined the data results for electric power consumption, that was decreased of about $2 \mathrm{kWh}$ the power consumption rather than used the manual system. Therefore, the use of tool cost-saving energy to control home lighting automatically proves to be more energy efficient than the manual system using the on/off switch. The future, this research would like to extend the system for costsaving energy tool to be controlled remotely and can be monitored in real-time. Resulted the tool systems will be the more flexible system to be controlled from anywhere as a request for high mobility of the household's owner.

\section{ACKNOWLEDGMENT}

The authors would like to convey a great appreciation to the Ocean and Aerospace Engineering Research Institute, Japan for supporting this research.

\section{REFERENCES}

[1] N. Almali, K.S. Bahir and O. Atan, "Arduino based smart home automation system", International Journal of Scientific Research in Information System and Engineering, Vol. 2 (2), pp 1-5, 2016.

[2] Sharef, Z.T. Isa, M.A., Hasan, F.A., Toorani M.A. dan Yadgar R.A., "Automated Meter Reading System Based on Basic Stamp2 Microcontroller", Asian Journal of Scientific Research, Vol. 6, No. 1, Pp. 88-97, 2013

[3] I. W. Shalat, "Simulasi pengaturan sistem penerangan secara otomatis dengan plc omron cpm1a 20cdr A-V1", pp 1-9, 2015.

[4] H. V. Dange and V. K. Gondi, "Powerline Communication Based Home Automation and Electricity Distribution System", International Conference on Process Automation, Control and Computing (PACC), Coimbatore, pp. 1-6, 2011

[5] J. T. Wiyatno, "Timer Digital Pengendali On/Off Peralatan Rumah Tangga Menggunakan Mikrokontroler Atmel 89S52", Jurnal Telkomnika, Vol. 3 (1), 2015.

[6] R. Panna, R, "Thesrumluk and C. Chantrapornchai, Development of Energy Saving Smart Home Prototype", International Journal of Smart Home, Vol. 7 (1), pp. 47-66, 2013.

[7] Arun R and Vuttaradi A, "Design of an intelligent and efficient light control system", International Journal of Computer Applications Technology and Research, Vol. 2 (2), pp 117-120, 2013.

[8] Li, Rita Yi Man; Li, HerruChing Yu, Mak, Cho Kei; Tang, Tony Beiqi, "Sustainable Smart Home and Home Automation: Big Data Analytics Approach", International Journal of Smart Home, Vol.10 (8), pp. 177198, 2016.

[9] R. Piyare, M. Tazil, "Bluetooth Based Home Automation System Using Cell Phone", IEEE 15th International Symposium on Consumer Electronics, 2011.

[10] I. Attia, Hamdy A., "Energy Saving Through Smart Home", The Online Journal on Power and Energy Engineering (OJPEE), Vol. 2 (3), pp. 223-227, 2011.

[11] A. E. Putra, Belajar Mikrokontroler Arduino Mega 2560 Teori dan Aplikasi, Edisi 2, Jakarta.

[12] Maxim Integrated, Datasheet RTC DS 1307, http://alldatasheet.com, 2017

[13] VISHAY, 20X4 Character LCD, available: http://www.vishay.com, 2017.

[14] PARALLAX INC, 4X4 Keypad Matrix, available: http://pdfdatabase.co, 2016

[15] SONGLE RELAY, Modul Relay SRD-05VDC-SL-C datasheet, available : http://alldatasheet.com, 2017.

[16] ALLEGRO, Sensor Arus ACS712 datasheet, available: http://alldatasheet.com, 2017.

[17] Daryanto, "Pengetahuan Teknik Elektronika", Jakarta, Penerbit Bumi Aksara, 2007. 